\title{
Mortality and serious injury of northern right whales (Eubalaena glacialis) in the western North Atlantic Ocean
}

\author{
Amy R. KnOwlton and Scott D. Kraus \\ New England Aquarium, Edgerton Research Laboratory, Central Wharf, Boston, MA 02110, USA \\ Contacte-mail: aknowlton@neaq.org
}

\begin{abstract}
Northern right whales in the western North Atlantic number about 300 animals and have shown little sign of recovery in recent decades. Mortality and serious injury due to human activities, particularly commercial fishing and shipping, are thought to be significant factors limiting their recovery. From 1970-1999, 45 right whale deaths were reliably documented. Sixteen of these fatalities (35.5\%) were due to ship collisions, and three $(6.7 \%)$ were due to entanglement in fishing gear. The remainder were neonates $(13 ; 28.9 \%)$ and 'unknown cause' mortalities $(13 ; 28.9 \%)$. Criteria for defining serious injuries and mortalities from entanglement or ship strikes were developed and include any animal carrying fishing gear, cuts from entanglement or ship strike deeper than $8 \mathrm{~cm}$, swelling or necrosis, evidence of poor health from such interactions, and, in carcasses, evidence of haematoma, haemorrhaging or broken bones. A total of 56 animals fitting the defined criteria were documented from 1970-1999: 31 (55.4\%) from entanglement and 25 (44.6\%) from ship strikes. Nineteen were fatal (16 ship strikes, 3 entanglements), 10 were possibly fatal ( 2 ship strikes, 8 entanglements) and 27 were non-fatal ( 7 ship strikes, 20 entanglements). The breakdown of potentially serious injuries by age and sex reveals no difference in levels between sexes but shows a $3.3: 1$ higher level of interaction in juveniles and calves versus adults. The data show that ship strikes are more immediately lethal, but entanglements can result in long term deterioration of an animal and may be responsible for higher levels of mortality than previously thought. Considering that some animals become entangled, drown and never return to the surface, even these levels may be underestimated. Between 1986 and 1999,84 animals were presumed dead based on a lack of resightings for six years. There were 32 confirmed deaths during this time period suggesting that at least as many unreported deaths occurred as carcasses were reported. Definitive actions need to be taken to reduce the level and severity of anthropogenic injuries and deaths. Actions could include continued disentanglement efforts, gear modifications, seasonal closures for fisheries, mandatory ship reporting, ships' routing measures and speed restrictions for commercial shipping.
\end{abstract}

KEYWORDS: RIGHT WHALE; STRANDINGS; ENTANGLEMENT; MORTALITY; SHIP STRIKE; FISHERIES; NORTHERN HEMISPHERE; ATLANTIC OCEAN

\section{INTRODUCTION}

Northern and southern right whales (Eubalaena sp.) were heavily harvested during the whaling era in which they were considered the 'right' whales to kill because they swam slowly, yielded good quantities of oil and baleen and floated after they were killed. Harvesting of northern right whales (Eubalaena glacialis) in the North Atlantic began in the 1100s off the coasts of Spain and France, continued off the coasts of Labrador and Newfoundland in the 1500s and 1600s (Aguilar, 1986), and persisted along the east coast of the US into the early $20^{\text {th }}$ century (Reeves and Mitchell, 1986b; Simpson and Simpson, 1988). Stocks were reduced to extremely low levels (Reeves and Mitchell, 1986a). Despite legal protection from hunting for both northern and southern right whales (Eubalaena australis) in 1935 by the 1931 Convention for the Regulation of Whaling and subsequent conventions (Donovan, 1992), the Northern Hemisphere populations have seen little to no recovery. This is in marked contrast to their Southern Hemisphere counterparts that have increased at a rate of $7-8 \%$ and have a current estimated abundance of about 7,000 animals (IWC, 2001b). Major factors thought to be contributing to this lack of recovery in the western North Atlantic include entanglement in commercial fishing gear and collisions with ships (IWC, 2001a). The purpose of this paper is to review available data on the extent and consequences of mortalities and serious injuries of right whales in this region.

Northern right whales have been studied extensively in the western North Atlantic by a collaboration of research organisations. Much of the work is based on photographically identifying individuals using callosity patterns on the head, as well as scars and markings on the body and tail (Kraus et al., 1986). Monitoring individual whales over time allows for a determination of the population status, reproductive rates, mortality levels, movements and demographic parameters. The western North Atlantic population is considered extremely endangered with about 300 individuals surviving (Knowlton et al., 1994; IWC, 2001a).

A previous review of right whale mortality and scarring rates (Kraus, 1990) indicated that $20 \%$ of the documented deaths were caused by ship collisions and $12 \%$ (later reduced to $6.7 \%$ - Kenney and Kraus, 1993; this manuscript) were caused by entanglement in fishing gear. Kraus (1990) also noted that $57 \%$ of all clearly-photographed living individuals bore evidence of entanglement interactions and $7 \%$ bore scars from ship collisions. The proportion of those injuries that would be considered serious was not assessed.

The impacts of serious injury from fishing gear on marine mammal populations were the focus of a workshop convened by the National Marine Fisheries Service (NMFS) in April 1997. One of the difficulties with assessing injuries in large cetaceans was identifying those likely to be 'serious', meaning reasonably likely to result in death or to impair reproduction (Angliss and DeMaster, 1998). Workshop participants felt an animal was not necessarily seriously injured if it was trailing gear and that a determination of effect would require a case-by-case assessment. It was generally agreed that any entanglement that impeded locomotion or feeding should be considered a serious injury. Although that particular workshop focused solely on entanglement injuries, the seriousness of injuries from other sources can also be difficult to assess. This paper attempts to outline criteria for assessing serious injury of right whales based on 20 years of observational data. It updates data on the number and causes of right whale deaths, provides information on the circumstances in which carcasses were first found (i.e. beached versus floating), the number of dead animals retrieved and the extent to which 
they were examined, and the location of carcasses relative to shipping lanes. Necropsy results and the indicators used to determine cause of death are reviewed. Information on the number of unconfirmed right whale mortalities is also provided.

Additional analyses are provided regarding the level and causes of serious injury observed in this population. Mortalities and serious injuries from human related activities are combined into categories based on the type of interaction, in order to assess the relative impact of each type of activity (e.g. fishing gear entanglement, ship strike) on the population beyond the figures calculated from known mortality data.

\section{METHODS}

\section{Mortalities}

The New England Aquarium maintains records of all right whale deaths documented by reliable means (e.g. photographs or positive identifications by persons trained in whale identification) from the western North Atlantic since 1970. These records typically include the location where the carcass was found, measurement data, a list of samples collected and a description of findings (including the cause of death, if determined). Not all records are complete. For example, in some cases, carcasses were observed at sea and never towed to shore for careful examination and in other cases carcasses were inaccessible or buried without a necropsy.

Determining cause of death is not a straightforward process. If there is external evidence of an interaction (propeller cuts, gashes, or entangled and drowned), assessing the cause of death can be relatively easy. However, other situations are much less obvious and require substantial effort and expertise to evaluate (broken bones, internal haemorrhaging, infection). Carcasses are usually several days old and have experienced severe decomposition, which masks histological and/or other features that might indicate trauma or stress. It has therefore recently been made a practice to flense each carcass to look for evidence of bone breakage. With apparent ship collisions, an assessment is made to determine if the incident was pre- or post-mortem. The indicators used to make an assessment include the four listed below:

(1) The location of propeller cuts and gashes

A dead right whale typically floats belly or side up, so post-mortem cuts or damage are likely to occur on the ventral side of the body. If an animal has evidence of cuts or gashes on the dorsal side of its body, it is assumed that the strike occurred pre-mortem (Kraus, 1990).

\section{(2) Length of time dead}

If an animal has been dead for less than a few days, as evidenced by the condition of internal organs, and there is evidence of ship collision, it is assumed that the ship strike led to the animal's death and did not occur post-mortem (Kraus, 1990).

(3) Evidence of internal haemorrhaging or haematoma Histology of internal organs and fluid found in body cavities can be useful for even moderately decomposed animals to identify haemorrhaging and blood clotting, which would only occur pre-mortem. Haematomas, which require circulatory action to form, can be looked for in association with broken bones to determine if the break occurred pre-mortem. Large haematomas found along the blubber/muscle interface can also indicate that an impact occurred.

\section{(4) Evidence of infection}

This is the most difficult indicator to confirm without a freshly dead carcass for histological samples. In rare cases, this has been inferred as the cause of death when an animal had a severely necrotic cut or gash in which exposed muscle and bone indicated infection was likely to have occurred.

All confirmed right whale mortalities have been tabulated by date, latitude, longitude, age, sex, length, disposition when found, extent of examination (e.g. whether it was retrieved or necropsied) and distance from the nearest shipping channel or lane (as determined from nautical charts) when first sighted. For each carcass, the cause of death was listed as ship strike, entanglement or unknown. Mortalities attributed to ship strikes or entanglements were based upon necropsy data or external evidence (e.g. missing tails, propeller cuts, or entangled and drowned). Mortalities listed as unknown were further sub-divided into newborn calves which died on the calving ground with no obvious indication of a human-related interaction, and all other deaths due to unknown causes. Most, if not all, neonates probably died of natural causes. The remainder classified as unknown probably fall in one of the three categories (ship strike, entanglement or natural cause) but there are no data to support assignment to any of these categories.

Confirmed deaths have been tallied for each five-year period beginning with 1970-74 and sub-divided by cause of death to assess trends over time. The initial disposition of the carcass (i.e. floating versus beached) and the number of floating carcasses actually retrieved were examined for each of these time periods to evaluate whether reports of floating carcasses have increased with heightened awareness of the plight of right whales and whether increased effort to document mortalities has significantly increased the retrieval of floating carcasses.

\section{Serious injuries and human-related mortalities}

The New England Aquarium curates the photo-identification catalogue of individual animals which allows for an assessment of the apparent health of each animal. Each animal's photographs were reviewed to assess the extent of interaction with fishing and shipping activity. Criteria were developed to define a serious injury based on longitudinal observations of right whales and the types of injuries that have been photographically documented. For an injury type to be deemed serious, at least one animal must have been observed to have either died or suffered potentially fatal wounds from the given injury type. This is a more stringent criterion than that proposed by the NMFS workshop.

\section{Criteria for serious injury and mortality caused by entanglements}

Three main criteria are used to determine whether serious injury or mortality resulted from entanglements in fishing gear.

\section{(1) Animal seen carrying line}

Events in which an entanglement and subsequent assisted or unassisted disentanglement were witnessed and occurred on the same day were not included.

(2) Open wound with a depth estimated to be greater than $8 \mathrm{~cm}$ caused by an entanglement

The $8 \mathrm{~cm}$ depth was chosen as some animals with cuts appearing only slightly deeper than this (as estimated from photographs) have been seen in poor health. Wounds were determined to be caused by entanglement if the cut wrapped around the injured body part (Hamilton et al., 1998). 
(3) Entangled animal, or animal with entanglement wounds appeared in poor health.

Indicators of poor health could include any one or more of the following: slow swimming; evident skin lesions; graying of skin; not fluking; evidence of infection (i.e. necrosis or swelling); and high levels of orange cyamids present in animals older than one year. One year was used as the lower limit because calves are often seen with high levels of orange cyamids on the head and sometimes the tail. As animals grow older these orange cyamids disappear and are seen associated only with injuries or on animals that are in poor health and are swimming slowly (Rowntree, 1996; Osmond and Kaufman, 1998).

\section{Criteria for serious injury and mortality caused by ship strikes}

Four main criteria are used to determine whether serious injury or mortality resulted from ship strikes.

(1) Propeller cut(s) or gashes which are more than approximately $8 \mathrm{~cm}$ in depth (see category (2) above)

(2) Evidence of bone breakage which was determined to have occurred pre-mortem

(3) Evidence of haematoma or haemorrhaging

(4) Ship-struck animal appeared in poor health

Indicators could include any one or more of the following: slow swimming; skin lesions evident; greying of skin; not fluking; and high levels of orange cyamids present in animals greater than one year old (see entanglement category (3) above), evidence of infection (i.e. necrosis or swelling).

\section{Sub-categories of ship strikes and entanglements}

The two human interaction categories, ship strike and entanglement, were each divided into four sub-categories based on the nature of the interaction. For entanglement these sub-categories were:

(1) line around tail;

(2) line through mouth;

(3) deep cuts but no line present;

(4) line around multiple body parts.

For ship strikes these sub-categories were:

(1) propeller cuts/gash;

(2) severed fluke(s);

(3) broken bones;

(4) haemorrhaging/haematoma.

The indications of poor health are potential secondary effects of each of these types of interactions and are described in individual animal accounts. Serious injuries from other causes are described only in the text. The mortality and photo catalogue databases were reviewed to determine the number of animals by sub-category. Each animal (living or carcass) in one or more of these sub-categories was then assigned an appropriate impact level: fatal; possibly fatal; or non-fatal. Fatal was only used for animals observed dead. Possibly fatal interactions included animals that were last seen in poor health or have not been seen since their initial injury sighting. This group was further subdivided into presumed dead if they have not been resighted for six or more years ${ }^{1}$ (Knowlton et al., 1994) or fate uncertain if they have not

\footnotetext{
${ }^{1}$ The six year criterion was developed to account for animals in this population that may be dead. Between 1980 and 1999, 23 animals or less than $8 \%$ of the population exhibited sighting histories longer than six years. Although this presumed dead criterion may over-inflate the actual number of dead animals, it serves as a cautionary approach to monitoring this population (see discussion in IWC, 2001a).
}

been resighted since being observed seriously injured within the past six years. Non-fatal interactions include animals that were seen with a serious injury but were subsequently observed alive and apparently healthy. Although some of the injuries in this non-fatal category could be deemed non-serious, there may be long-term impacts from such interactions that are impossible to measure. For the purposes of this paper, therefore, the non-fatal injuries are all considered serious injuries. Included in these summaries are animals that were not photo-identified but for which there exists either qualified observer information on a human activity/right whale interaction to suggest that the resulting injury was definitely serious, or carcasses with external evidence of a ship strike or entanglement interaction which could not be matched to the right whale photo-identification catalogue because of insufficient documentation.

To assess the combined effects of serious injuries and mortality over time, five categories (natural mortalities, unknown cause mortalities, fatal injuries, possibly fatal injuries and non-fatal injuries) have been plotted by year (Fig. 2). A linear regression was carried out for the years 1980-1999, the years in which data were collected systematically.

\section{RESULTS}

\section{Mortality}

Forty-five right whale mortalities were documented from 1970-1999 (Table 1). The number of carcasses observed per year ranged from $0-6$ with a mean of $1.50(\mathrm{SD}=1.36$; Fig. 1$)$. Out of the 30 years that mortality data have been collected, there were only six years during which a death was not documented, all prior to 1986 .

Mortalities by cause of death for each five-year period beginning with 1970-1974 are shown in Fig. 2. The increase in total mortalities for each five-year period is significant at $p=0.024$. Ship strike mortality shows a generally increasing but not quite significant trend over time $(p=0.064)$ and no trends are obvious for newborn calves $(p=0.267)$, entanglement $(p=0.119)$ and unknown cause $(p=0.210)$ mortalities.

Ship strikes account for the largest number of confirmed deaths $(16 / 45,35.5 \%)$. Nine out of the 16 ship strikes (56.3\%) have occurred since 1990 , representing $47.4 \%$ of the total mortalities for this period (9/19). Mortality of neonates with no evidence of human interactions represent $28.9 \%(13 / 45)$ of the total mortality ${ }^{2}$. Entanglement-related deaths represent $6.7 \%$ of total confirmed mortality (3/45) and deaths due to unknown causes represent $28.9 \%$ of total confirmed mortality (13/45).

The number of carcasses found floating versus beached, and the number of floating carcasses retrieved, were plotted for each five-year period (Fig. 3). The data indicate that in recent years, a greater number of floating carcasses was observed and reported which may account for the apparently increasing mortality trends. Of the 17 carcasses found floating, ten were retrieved. Seven of these ten carcasses were retrieved within the past five years, indicating the greater commitment to retrieving every right whale carcass. Three carcasses were first reported floating but subsequently washed ashore. These animals were included in the beached category.

\footnotetext{
2 The foetus found on 10 September 1989 was probably the foetus of \#1219 that died of unknown causes. The foetus was found three miles south of 1219's carcass and during a month when right whales are typically not sighted in that region. The foetus was counted as unknown cause mortality.
} 


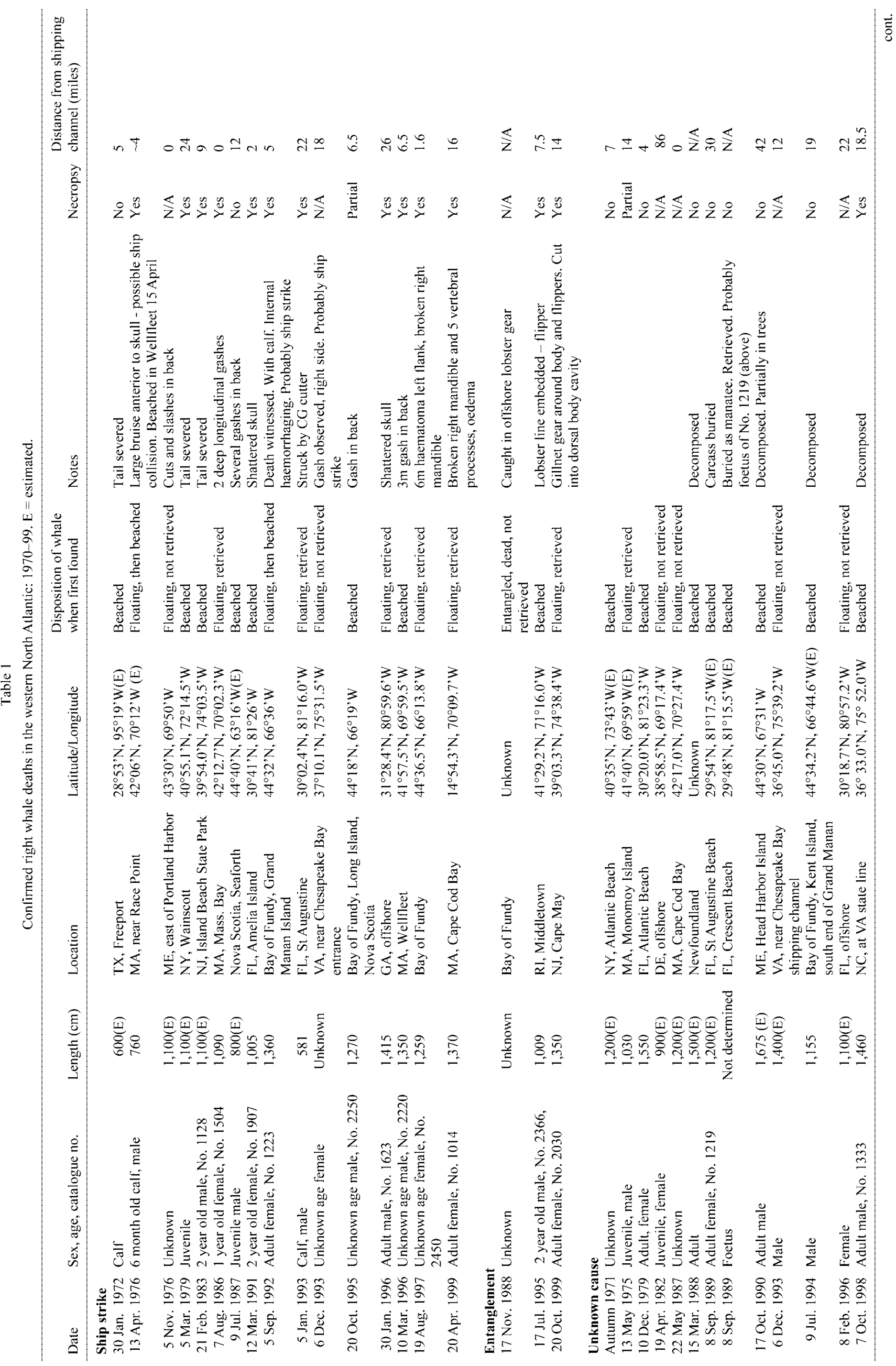




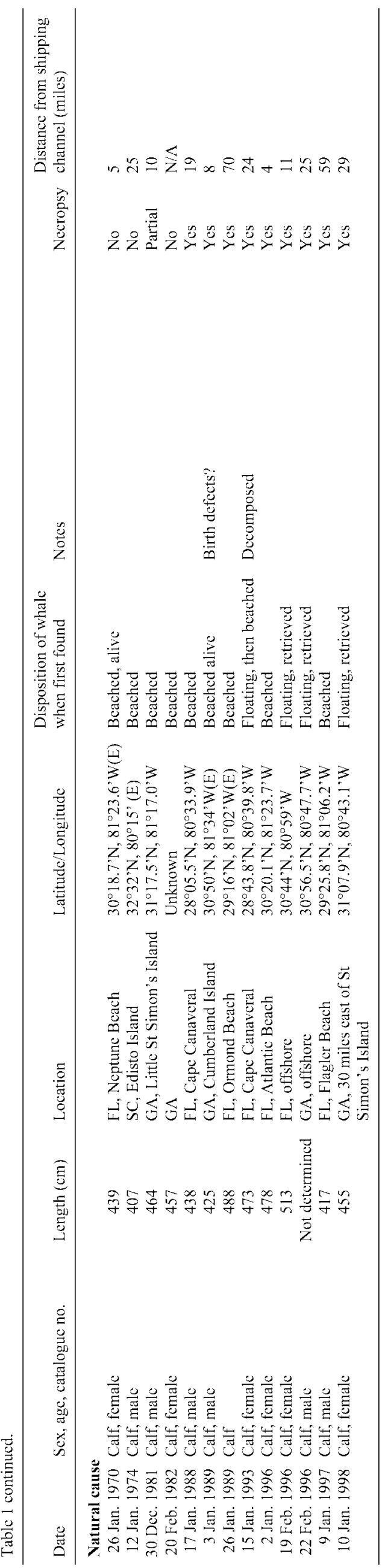




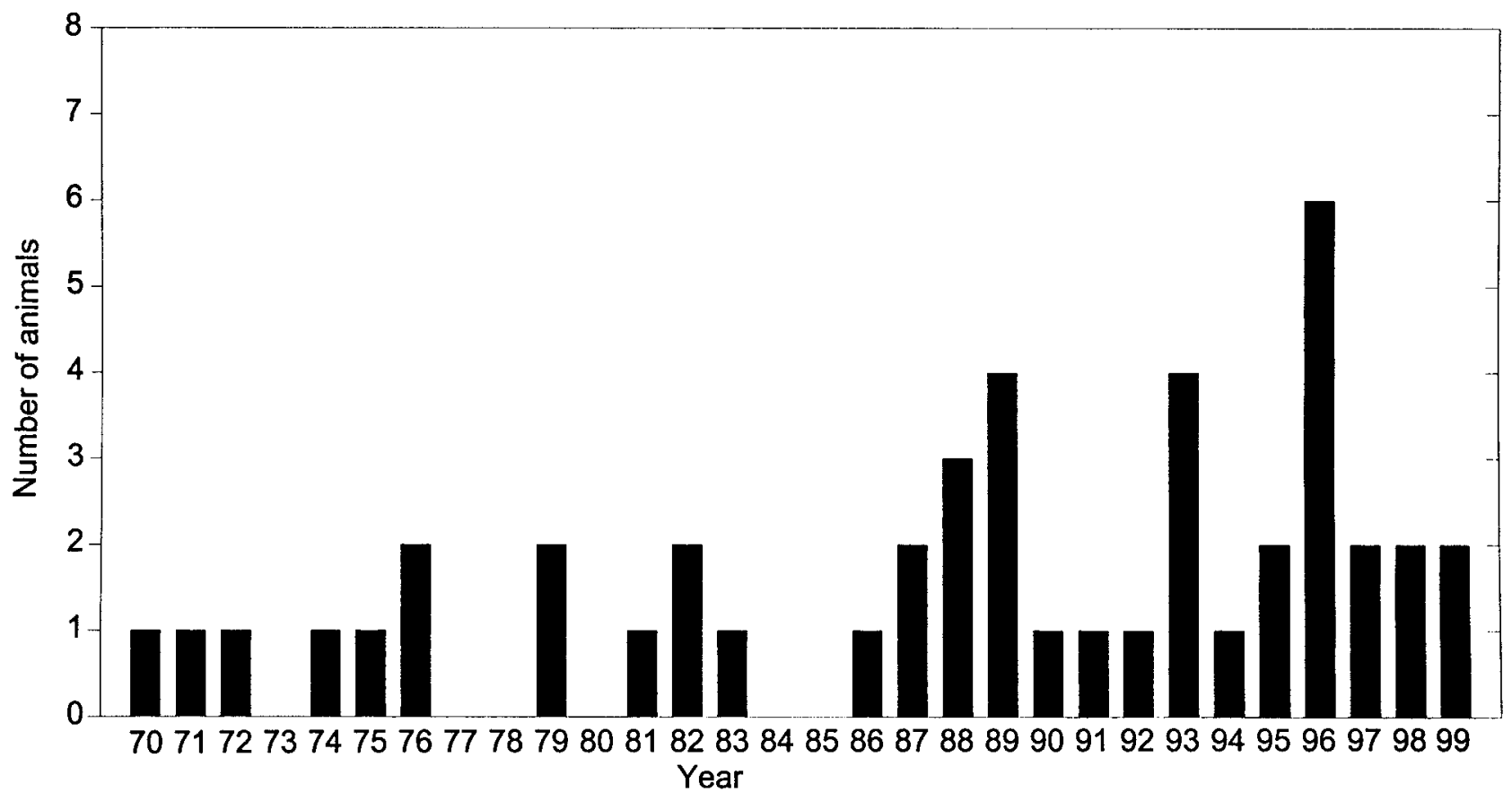

Fig. 1. Confirmed right whale fatalities by year.

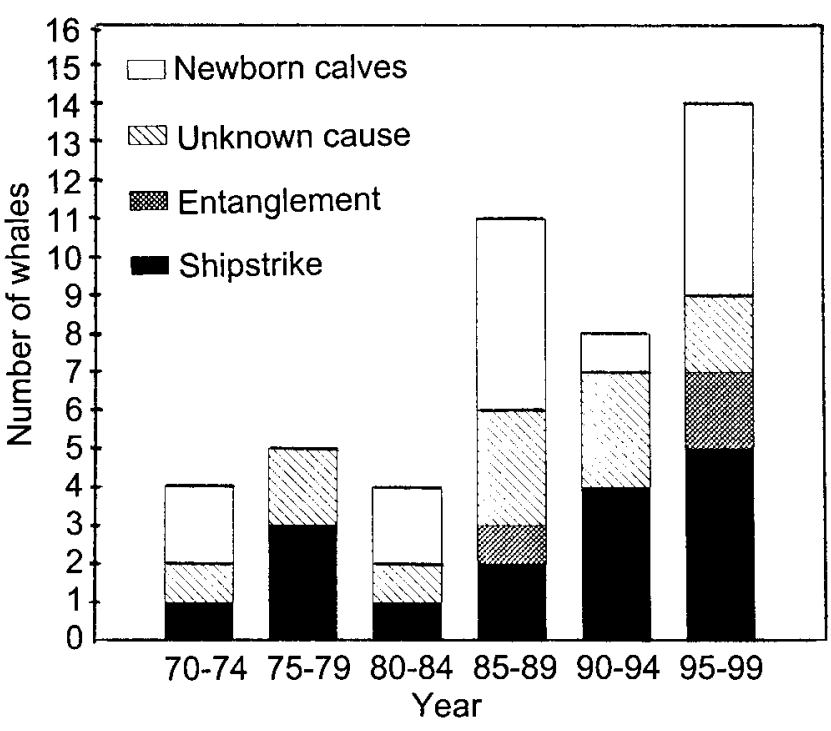

Fig. 2. Confirmed right whale fatalities by cause of death, 1970-99.

Of the 38 carcasses that were retrieved or beached, 26 were partially or fully necropsied (see Table 1). The thoroughness of each necropsy varied depending on the accessibility of the carcass, access to heavy equipment to move the carcass and aid in flensing, availability of qualified personnel, and availability of adequate funds to carry out the necropsy (note: the financial situation improved dramatically after 1996 when the US National Marine Fisheries Service (NMFS) committed resources to respond to all right whale mortalities).

For the 16 carcasses known to have been struck by ships, the distances to the nearest shipping channel ranged from 0-26 miles with an average distance of 9.9 miles $(\mathrm{SD}=8.7$ miles). For 25 of the 29 remaining carcasses (location data were not available for four animals), the distances to the nearest shipping channel ranged from 0-86 miles with an average distance of 23.1 miles ( $\mathrm{SD}=24.0$ miles). This difference was not quite significant at a level of $p=0.081$ (Mann-Whitney rank sum test). Three of the 13

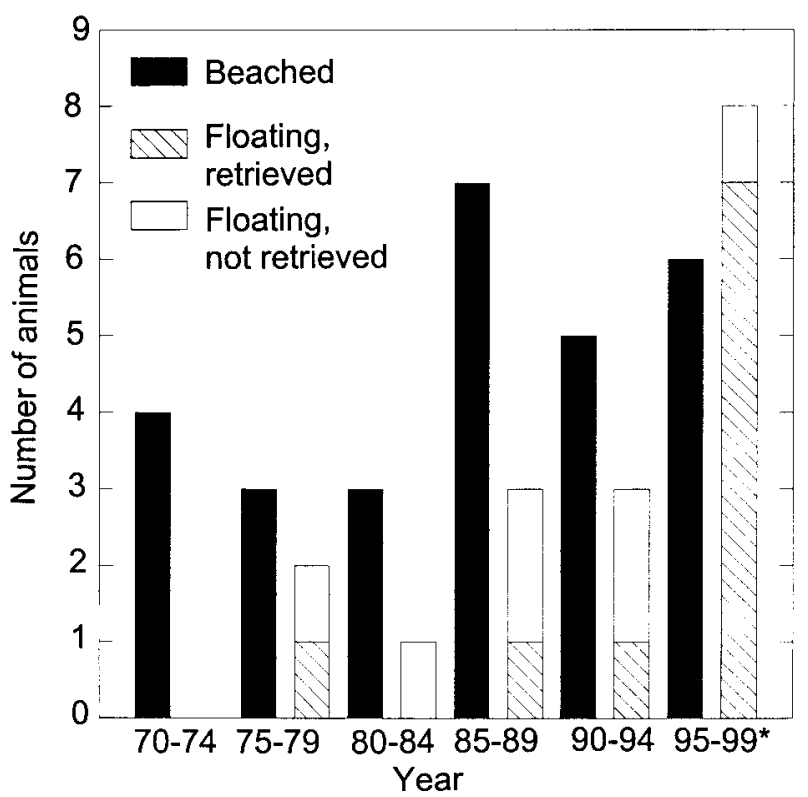

Fig. 3. Number of beached versus floating carcasses.

non-neonatal, unknown cause mortalities were found within nine miles of shipping lanes and an additional five unknown cause mortalities were found between nine and 26 miles (maximum distance where ship struck carcasses were found) suggesting that some proportion of these unknown cause mortalities could be attributable to ship strikes. The locations of these 41 carcasses in relation to shipping lanes and the coastline are displayed in Figs 4-6.

There were three additional deaths that were initially reported as right whales but were not reliably confirmed as to species, and therefore were not included among the confirmed right whale deaths: (1) 15 February 1983 - a carcass pulled up by a fishing vessel was inconclusively identified as a right whale (Kenney and Kraus, 1993); (2) 6 July 1991 - a calf with two other larger whales was struck by the US Coast Guard cutter Chase approximately 73 miles east of the Delaware Bay shipping lanes. Although Coast Guard personnel identified the animal as a right whale, the 


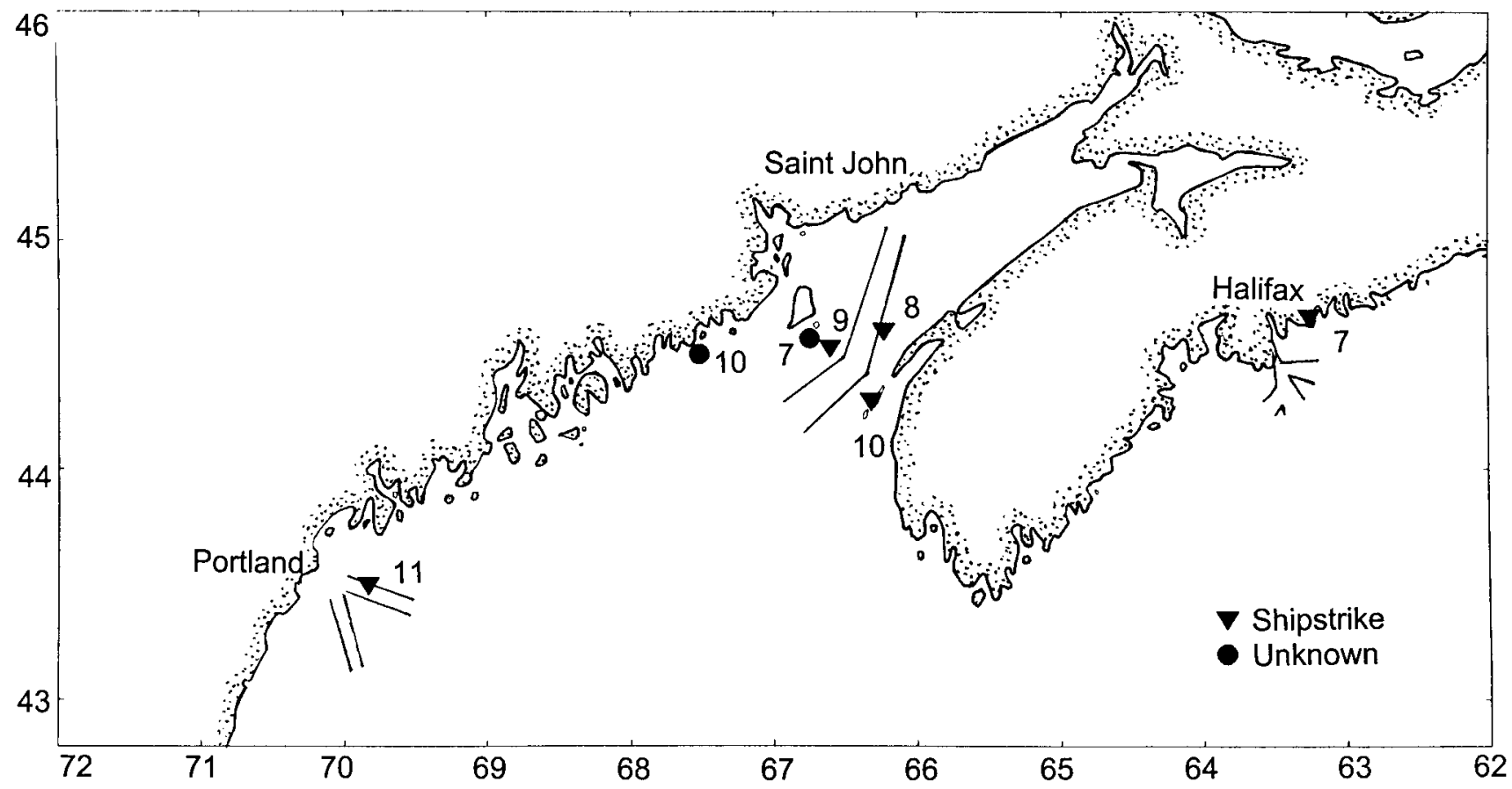

Fig. 4. Right whale fatalities and shipping lanes in the Gulf of Maine and Canada, 1970-99. Note: the number next to the symbol represents the month the carcass was detected.

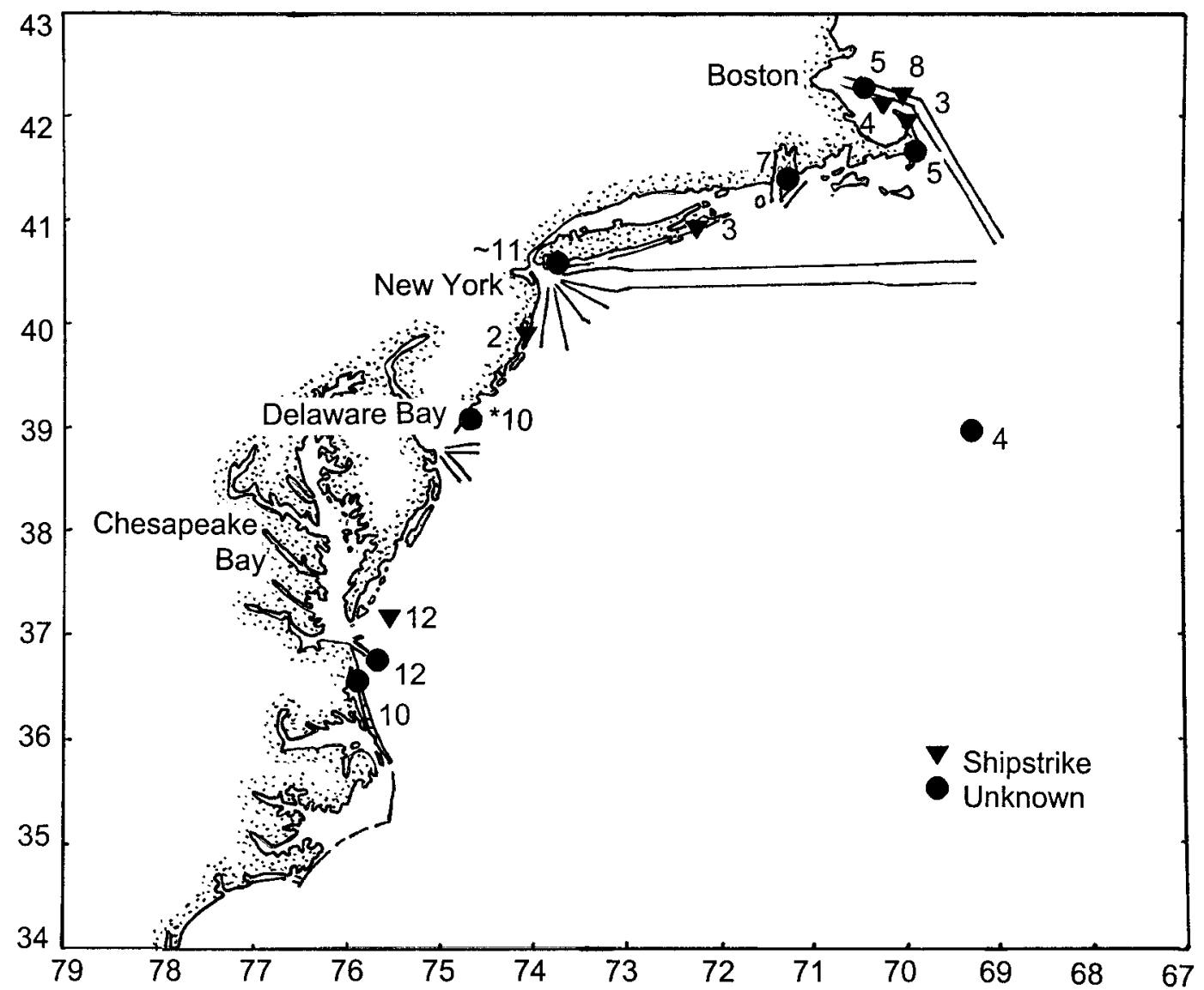

Fig. 5. Right whale fatalities and shipping lanes in southern New England and the mid-Atlantic coast, 1970-99. Note: the number next to the symbol represents the month the carcass was detected. An asterisk in front of the number indicates an entanglement mortality.

timing and location of the strike suggest it may have been a sperm whale. These two species are often confused by inexperienced observers; (3) 25 March 1996 - a possible right whale carcass was reported by a Navy submarine 80 miles east of the northeast Florida coast. The carcass was not relocated by aerial surveillance.
In addition, in the Kraus (1990) review of mortality, there was one event tallied as a definite right whale death that has been deleted from the above list of confirmed deaths because a carcass was not observed. This record involved a right whale observed in July 1984 entangled in a cod trap. The observer, a qualified whale biologist, was certain the whale 


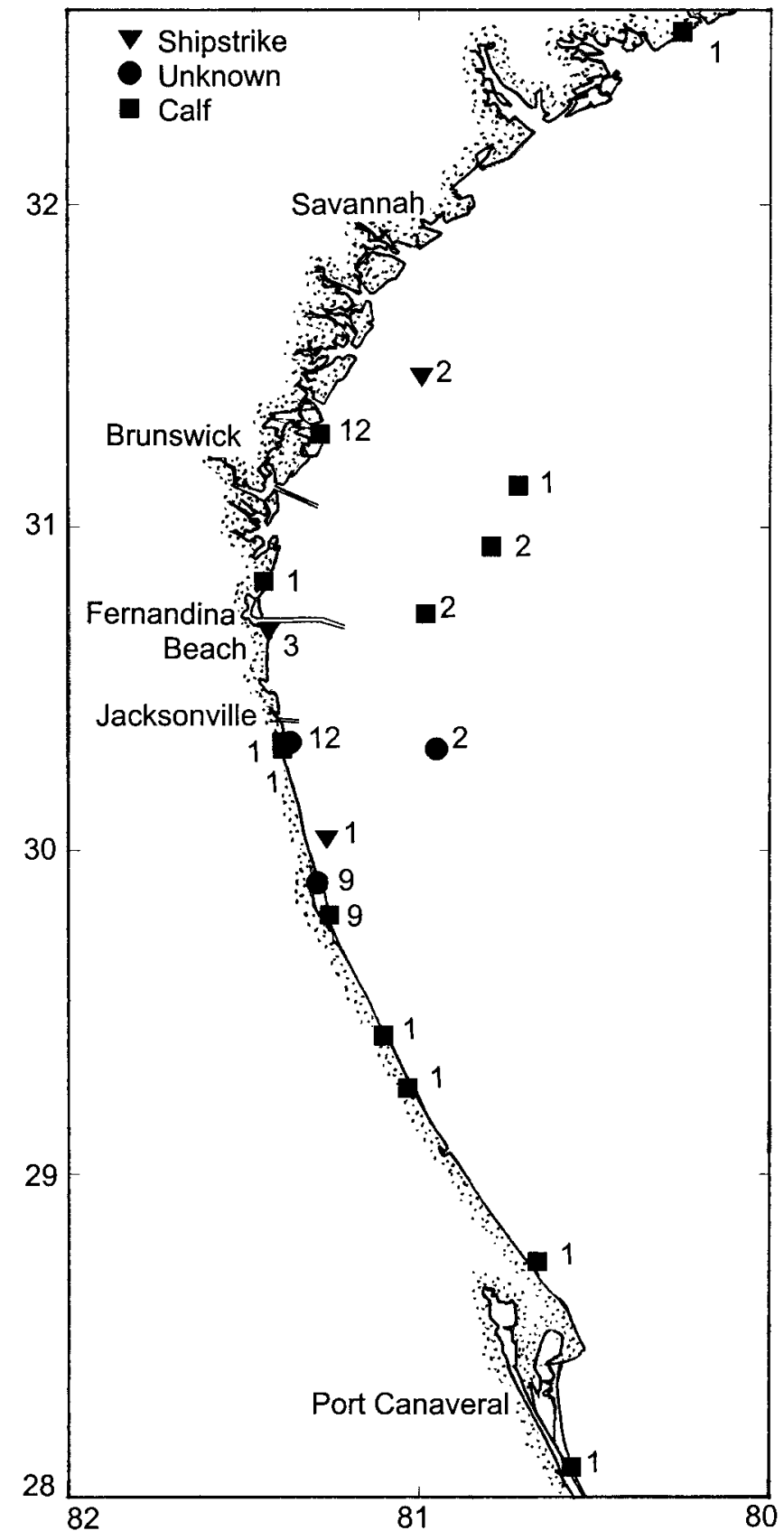

Fig. 6. Right whale fatalities and shipping lanes in the southeast US, 1970-99. Note: the number next to the symbol represents the month the carcass was detected.

would not survive the entanglement (Jon Lien, pers. comm.), but since a carcass was never detected, this event has been moved to the serious injury/presumed dead category as described below.

\section{Serious injuries and human-related mortalities}

Fifty-six right whales fitting the serious injury criteria described above have been documented since 1970 (Table 2). Thirty-one $(55.4 \%)$ were the result of entanglements in
Table 2

The age and sex of right whales identified with serious injuries:1970-99.

\begin{tabular}{lcccc}
\hline & Calf/juvenile & Adult & Unknown age & Total \\
\hline Female & 13 & 6 & 2 & 21 \\
Male & 9 & 3 & 7 & 19 \\
Unknown sex & 7 & 0 & 9 & 16 \\
Total & 30 & 9 & 18 & 56 \\
\hline
\end{tabular}

fishing gear and 25 (44.6\%) were caused by ship strikes. Four animals bore serious injuries from both ship strike and entanglement but were counted in the category considered the more serious interaction; one animal suffered three separate serious entanglement events with two disentanglements. Nineteen of the 56 injuries (33.9\%) have resulted in documented fatalities (16 ship strikes, 3 entanglements as described in the Mortalities section above). Ten other injuries $(17.9 \%)$ were considered possibly fatal interactions, including seven animals presumed dead (i.e. not resighted for six or more years since being injured) and three others which were seen seriously injured since 1994 and, unless they are resighted, will become presumed dead in the years ahead. The remaining 27 animals (48.2\%) suffered injuries that were determined to be non-fatal. Three additional animals not included in the above tally had serious injuries that were not attributable to human interactions. One animal (\#1217) was missing about $1 \mathrm{~m}$ of the left fluke due to attack by killer whales as evidenced by tooth marks around the injury. This was a non-fatal injury. A second animal (\#1025, a reproductively active female) is presumed dead since she was last seen in 1983 with drooping flukes, the cause of which is unknown. A third animal (\#1505, an adult male) was seen in April 1999 in very poor condition evidenced by emaciation, skin lesions and orange cyamids on the body. A longitudinal cut at least one metre long was observed near the tail stock but it was impossible to tell from the photos the depth of the cut or what caused it, thus the cause of this animal's condition is unkown.

The breakdown by age and sex of these 56 animals is provided in Table 2. There was no significant difference in injury levels by sex (19 male versus 21 female) when compared to the 1999 population sex ratio of $52 \%$ male to $48 \%$ female using a chi-square test $\left(0.9>\chi_{0.061}^{2},>0.5\right.$, d.f. =1). However, the number of calves and juveniles recorded with serious injuries was more than three times higher than known adults (30 versus 9), which is significantly greater than the proportion of juveniles and calves in the population in $1999\left(19 \% ; \chi^{2}{ }_{58.560}, p<0.001\right.$, d.f. $=1$ ). Eighteen animals of unknown age had injuries but some proportion of these animals likely acquired the injury as juveniles so the ratio of injured calves and juveniles to injured adults may well be greater than $3.3: 1$.

The level of impacts from each of the serious injury criteria is given in Fig. 7. A detailed description of each animal's serious injury is given in Table 3 . 
J. CETACEAN RES. MANAGE. (SPECIAL ISSUE) 2, 193-208, 2001

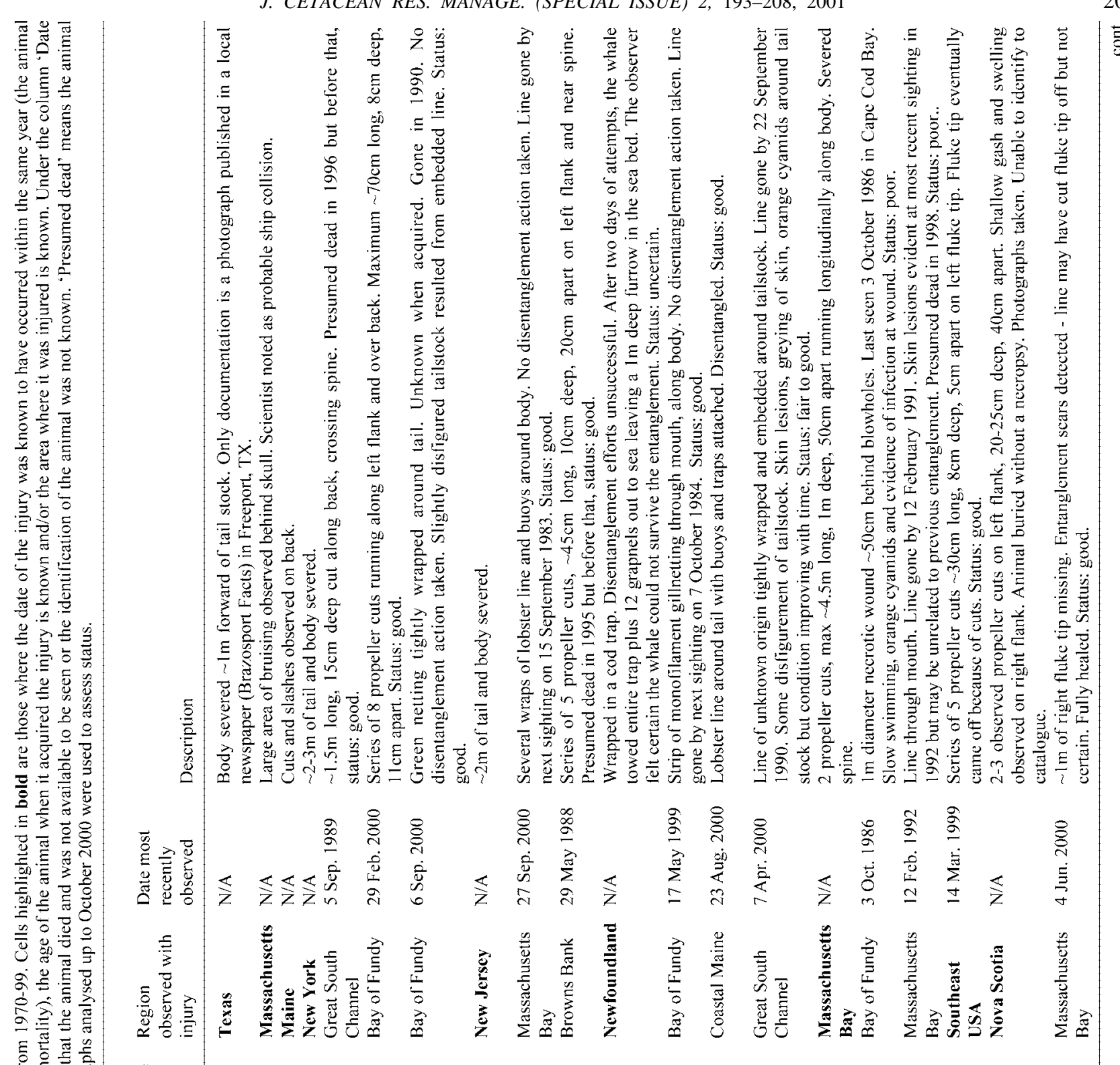

政要

这势

要

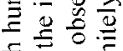

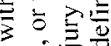

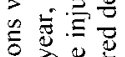

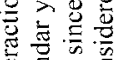

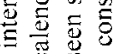

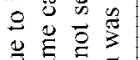
惢

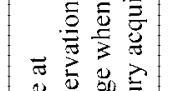

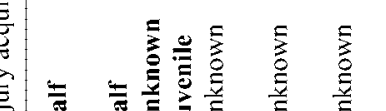

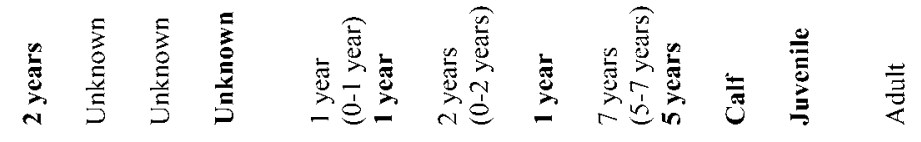$$
\text { ॐ } \supset \Sigma \supset \Sigma \Sigma \Sigma \Sigma \Sigma
$$

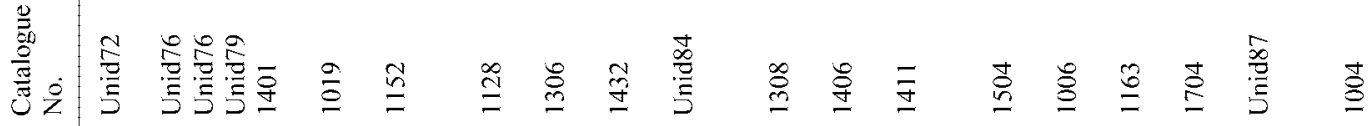

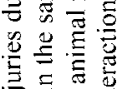

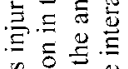

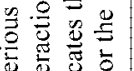

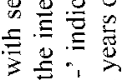

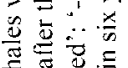

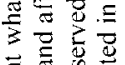

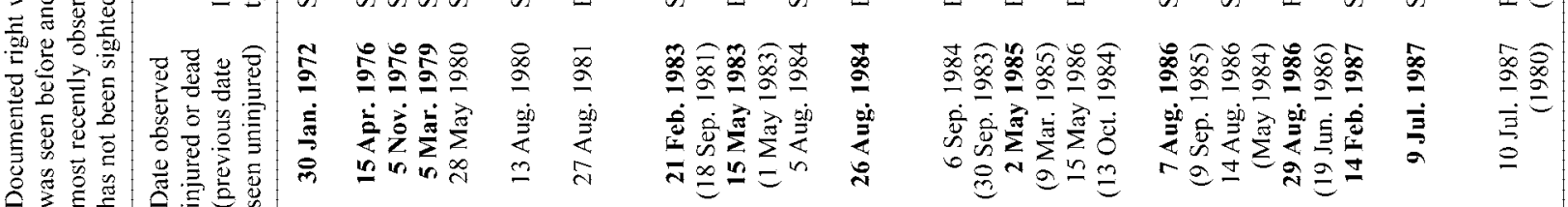

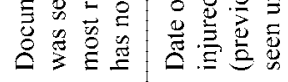




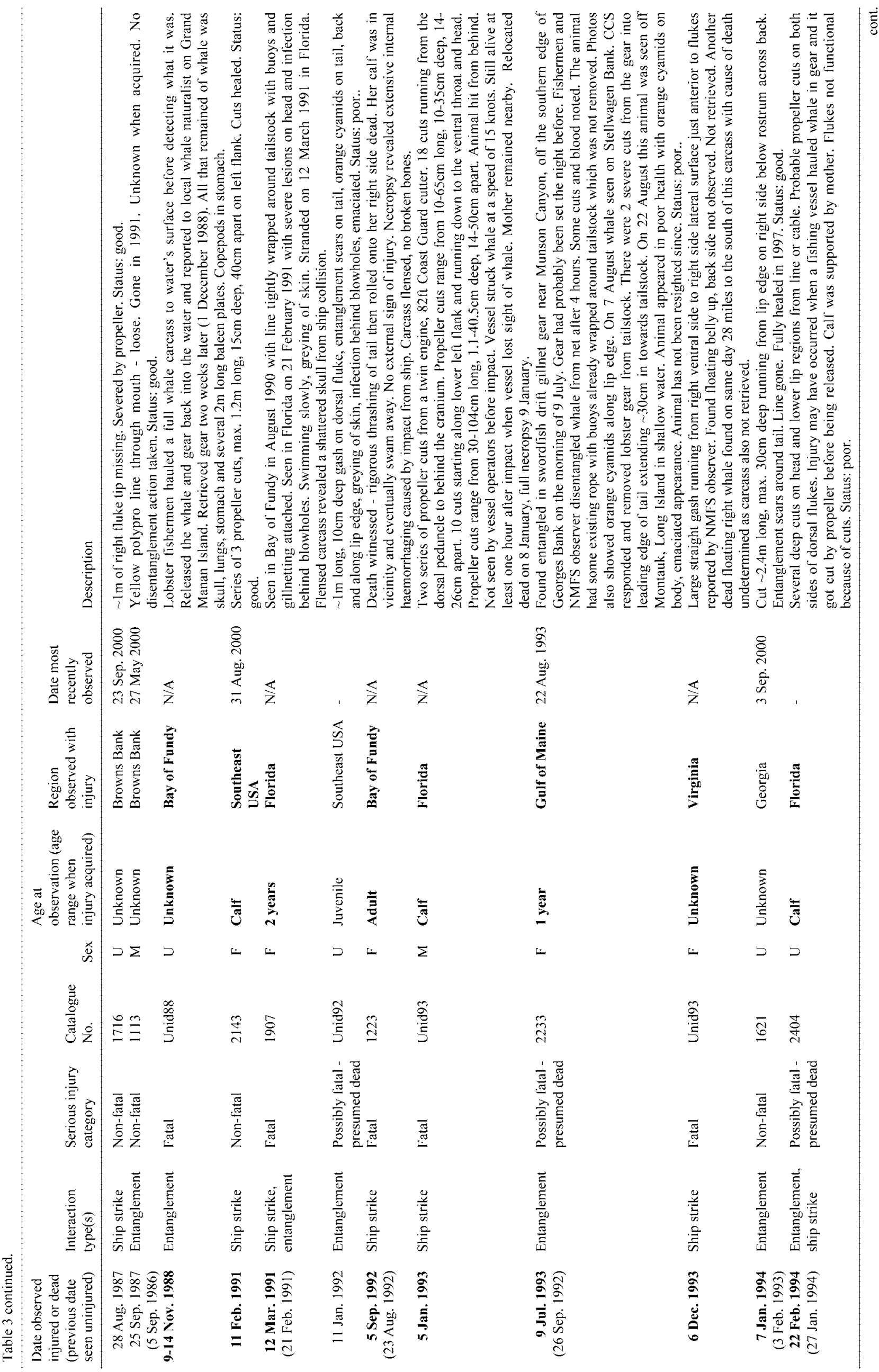


J. CETACEAN RES. MANAGE. (SPECIAL ISSUE) 2, 193-208, 2001

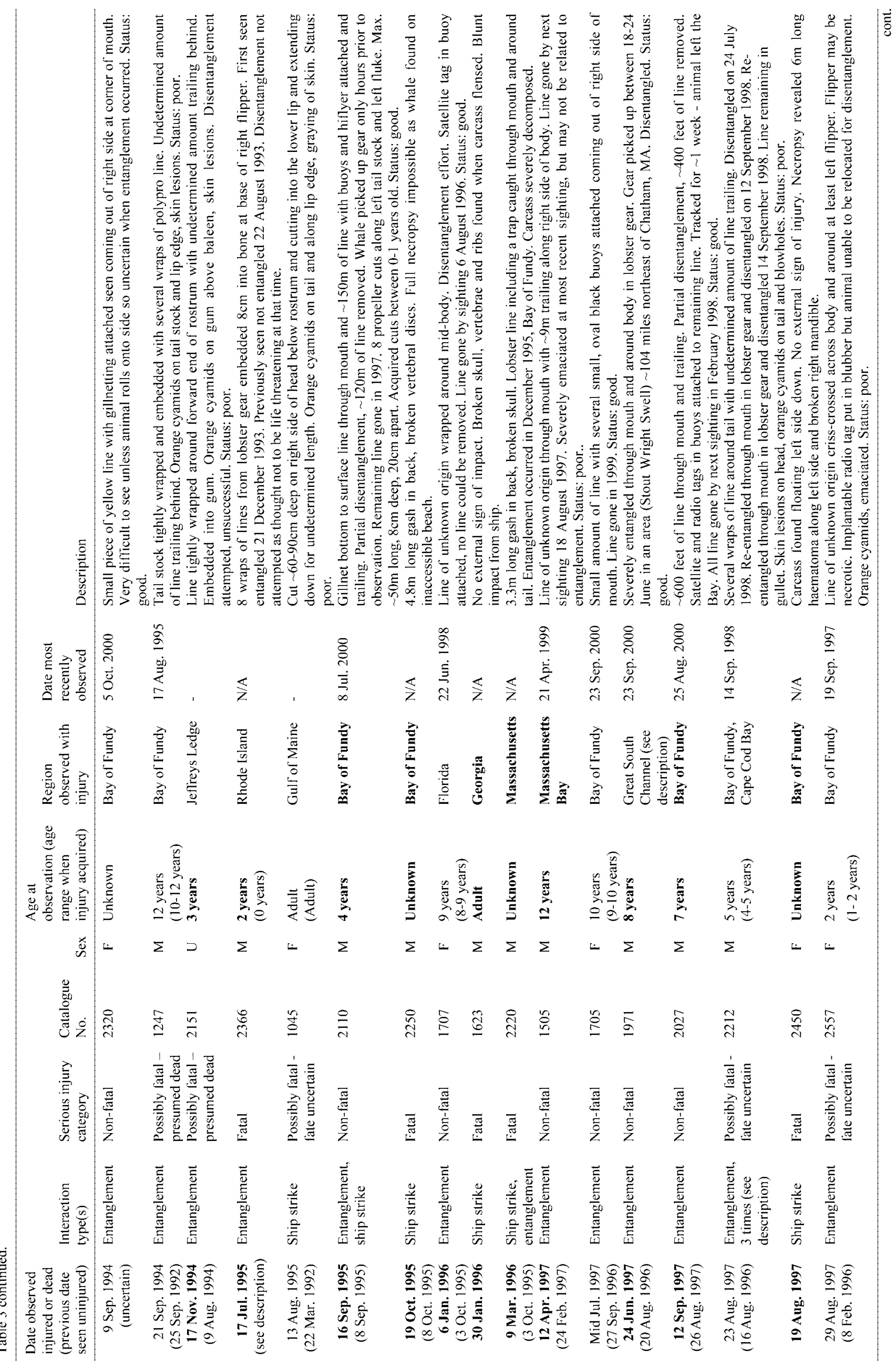




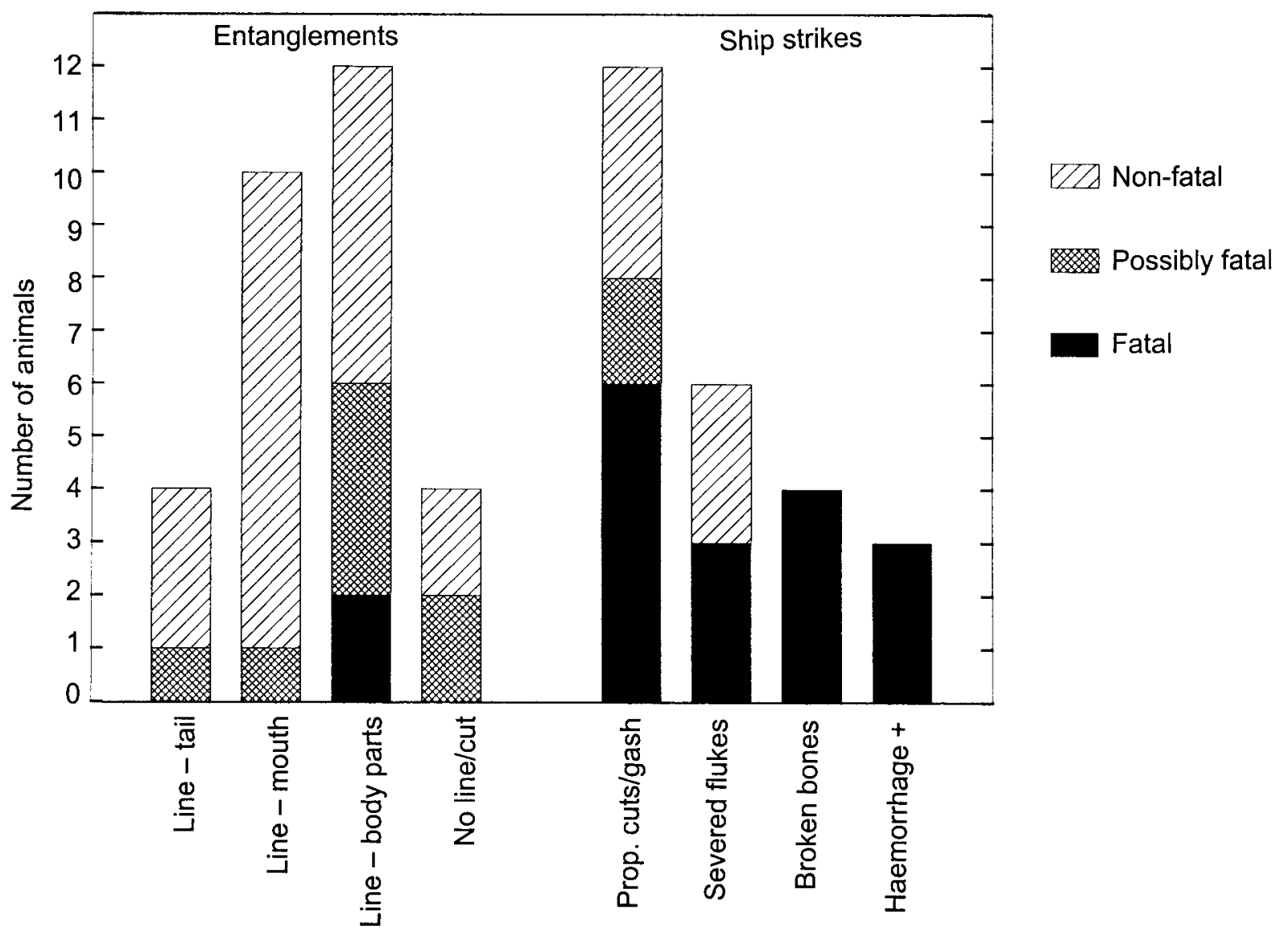

Fig. 7. Comparison of impacts of entanglements and ship strikes.

Ship strikes resulted in a high level of observed fatalities (28.6\% of all serious injuries). Propeller cuts and gashes resulted in the most lethal injuries with six fatalities documented. Four fatalities occurred in the broken bones category, three fatalities in the severed flukes category and three fatalities were documented in the haemorrhaging/haematoma category. In the severed fluke(s) category, only those animals where the whole tail was severed were found dead. The animals that suffered non-fatal injuries from severed fluke(s) only had up to one side of the tail cut off. There were only two animals categorised as having possibly fatal injuries due to ship collision. With 18 documented or presumed mortalities among 25 recorded vessel-related serious injuries and only seven non-fatal ship strike injuries, it appears few whales successfully survive ship collisions.

Only three carcasses were found where the primary cause of death was attributed to entanglement $(5.3 \%$ of all serious injuries). All had line around multiple body parts. One of these animals was found entangled and drowned in lobster gear (unid88). Another had line through the mouth and tightly wrapped around its flipper and embedded $8 \mathrm{~cm}$ into the bone (\#2366) - it is suspected that this animal died from infection. The third animal (\#2030) had lines from a gillnet wrapped tightly around her body and both flippers. Despite extensive disentanglement efforts, the embedded line could not be cut and it eventually sawed into her body cavity resulting in death. In addition, eight of the 10 possibly fatal injuries were from entanglements. The line around multiple body parts sub-category accounted for four of the eight possibly fatal injuries. Although two of these animals were disentangled (\#2233 and \#2212), the injuries in \#2233's case were so severe that this animal probably died. With respect to \#2212, the animal looked in poor health during the latter disentanglement plus there was some line remaining in the gullet, so its fate remains uncertain. Considering that one of the right whales that died from entanglement drowned and never floated to the surface, entanglements may be responsible for an additional number of undocumented right whale deaths.

Nine of the 20 non-fatal entanglement injuries fell within the line through the mouth sub-category. Two of these 9 were partially or fully disentangled which may have reduced the severity of their situations. The high number of animals in this category suggests that catching line in the mouth is the most frequent type of serious injury, and if the animal can break away from the attached gear and not become further entangled, the impact may not be severe. Six of the 20 non-fatal entanglements were in the multiple body parts category. Full or partial disentanglement was carried out for four of the six which definitively reduced the severity of the impact.

If the possibly fatal injuries (10) are all assumed to be fatal and are added to the total of confirmed deaths $(45+10=55)$, then entanglements (11) represent $20.0 \%$ of the right whale mortality between 1970 and 1999, ship strikes (18) account for $32.7 \%$, and unknown causes (26) represent $47.3 \%$. When neonate mortalities (13 or $23.6 \%$ ) are excluded from the total, the resulting percentages are: entanglements $26.2 \%$; ship strike $42.9 \%$; and unknown cause $30.9 \%$. Thus, once neonate mortalities are removed, anthropogenic interactions are responsible for a minimum of $69.0 \%$ of the confirmed and possible mortalities (29/42). This is substantially higher than that reported by Kraus in 1990 (53\%).

A graph showing all potentially serious injuries and confirmed deaths by year (Fig. 8) indicates an increasing trend, especially evident in the mid 1990s. A regression analysis using natural log transformation of the dependent 


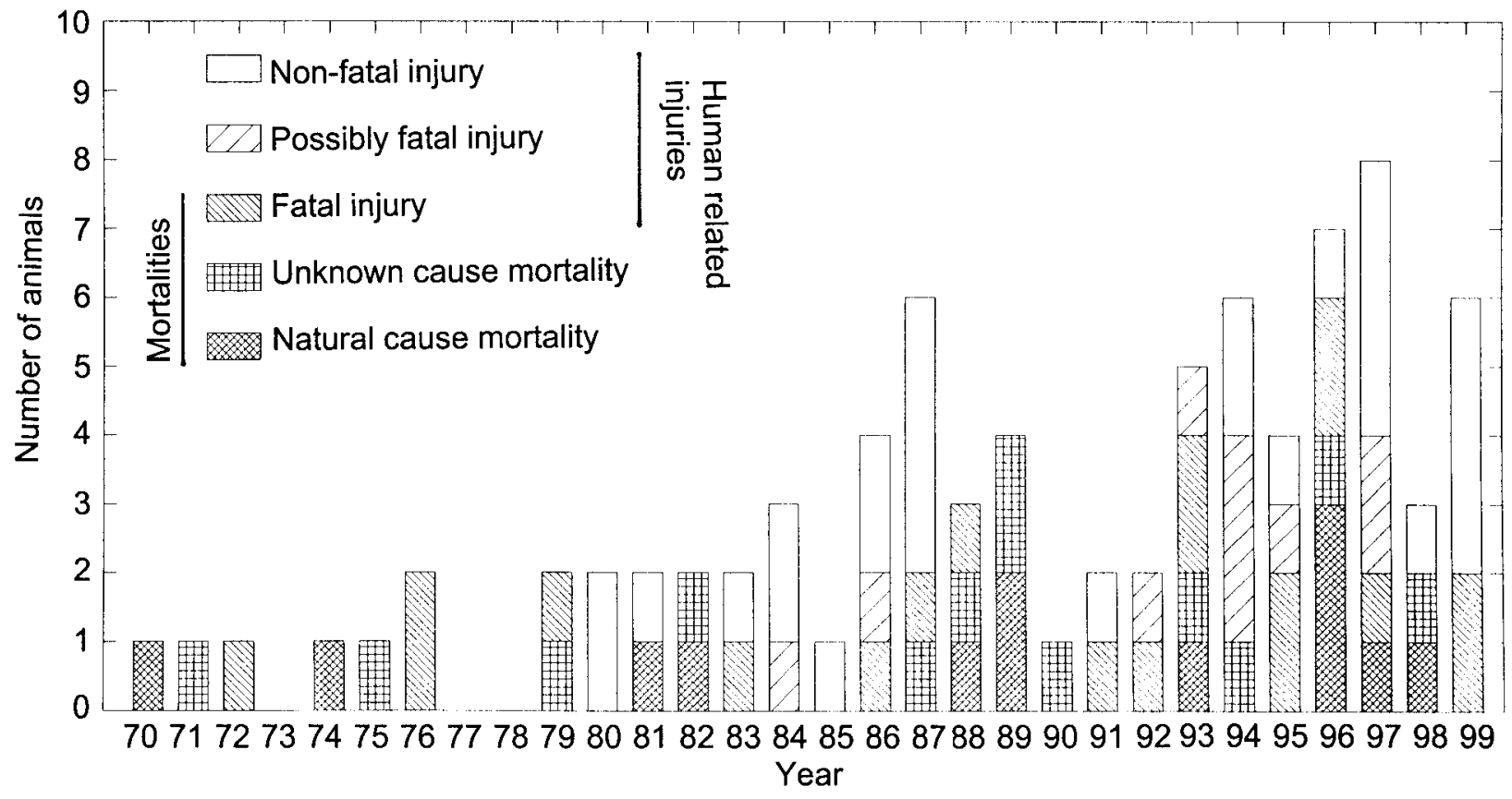

Fig. 8. All potentially serious injuries and mortalities.

variable for the data from 1980-1999 (data prior to 1980 were not collected systematically) reveals a significant increase over time $(\mathrm{p}=0.009)$ with an annual rate of increase of $5.83 \%(95 \% \mathrm{CI}=1.85 \%$ to $9.81 \%)$.

\section{DISCUSSION}

Western North Atlantic right whales face significant impacts from interactions with ships and fishing gear that are impeding the populations' ability to recover from nearly a millennium of whaling pressure (Caswell et al., 1999; IWC, 2001a). Previous analyses of the extent of these interactions have focused on confirmed deaths and the frequency of scars from interactions with human activities (Kraus, 1990). In the 1990s, a series of developments indicated that anthropogenic interactions resulting in serious injury to members of this population were a greater cause for concern than previously thought. Firstly, the observed number of severe entanglements which could potentially prove fatal to individual right whales increased. Of the 11 fatal or possibly fatal entanglements recorded, all but one were documented in the 1990s. Secondly, the number of documented ship strike deaths increased with nine out of the 16 occurring since 1990 (although some of this increase is probably due to increased attention to the reporting, retrieval and necropsy of right whale carcasses, which may simply mean that deaths attributable to ship collisions were underestimated in the past). Thirdly, an 'unusual mortality event' occurred during the winter of 1995/96 when eight right whales died over a nine month period: five along the southeast US coast, one near Rhode Island, one in Canadian waters and one near Cape Cod. Three of those animals died from ship collisions. Finally, the 1994 amendments to the US Marine Mammal Protection Act were passed which required that serious injury and mortality among endangered marine mammal species from entanglements in fishing gear would have to be reduced to levels approaching zero within five years of implementation of a Take Reduction Plan (TRP). An Interim Final Rule outlining the plan was put in place in July 1997, and a Final Rule was issued in February 1999.
There are a number of reasons to suggest mortality data alone provide an incomplete picture of anthropogenic interactions. The data show that ship strikes are often immediately fatal. If the animal in the collision is healthy with a thick blubber layer it will float and have a relatively high probability of being detected and reported. On the other hand, a whale that is entangled is less likely to die immediately unless it drowns, in which case it may be held underwater by attached gear and be less likely to be detected and reported. Moreover, if it survives for some time, an entangled whale that carries the gear could become emaciated because of impaired feeding or the extra energy expenditure imposed by carrying heavy fishing gear. If this animal dies, either the emaciation or the weight of the gear could cause the carcass to sink and not be detected. Therefore, mortalities resulting from entanglement may be considerably underestimated if only the documented mortality database is assessed.

The average annual rate of increase in serious injuries and mortalities $(5.83 \%)$ exceeds the calculated population growth rates. Although the range falls within the average annual rate of increase for the population calculated as $2.5 \%$ by Knowlton et al. (1994) and 4.4\% by Caswell et al.(1999) for the years 1986-1992, Caswell et al.'s (1999) results indicate that the population is presently decreasing at a rate of $2.4 \%$ per year. Thus, this increasing rate of serious injury and mortality does not appear to be correlated to population size. In addition, an analysis of the average mortality rate for the years 1993-1999 (as defined in Knowlton et al., 1994) shows an average mortality rate of $3.37 \%$, up from the rate of $2.1 \%$ for $1986-1992$. This rate is higher than the $1-2 \%$ mortality rates detected in healthy populations and is definitely cause for concern.

The long-term impacts of non-fatal injuries are difficult to assess. For example, animal \#2143 suffered deep propeller cuts on the left flank but has been resighted numerous times since the injury and still appears healthy. This female was born in 1991 and should be approaching reproductive age, but it is not clear whether she will be able to reproduce as a result of her extensive injuries. Another female \#1163, was entangled through her mouth in 1986 but had lost the gear by 
1991. Although she seemed healthy while carrying and shortly after losing the line, she developed extensive skin lesions a year later and is now presumed dead; it is unclear whether these lesions were related to the entanglement.

The number of mortalities that go undetected could still be quite high even with increased awareness and reporting. Considering information on the number of right whale births, estimated population size and growth rates, and mortality, the Marine Mammal Commission (1995 Annual Report) suggested about two-thirds of all right whale mortality in the western North Atlantic goes unreported. Another means of estimating this proportion is through the analysis of presumed mortalities as indicated by the number of animals in the right whale photo catalogue that have not been seen for six years and which are presumed dead in the sixth year after the last sighting (Knowlton et al., 1994). Between 1986 and 1999, 84 animals were presumed dead from the absence of resighting records in the photo catalogue as compared to 32 confirmed deaths for a ratio of 2.6:1. Although the number of presumed dead whales is likely to be inflated owing to the vagaries of survey effort and the fact that some confirmed deaths could not be examined to determine if they were among the presumed dead animals, it seems reasonable to believe that at least as many unreported deaths occurred as reported carcasses during this 14-year period.

Caswell et al. (1999) note a declining survival probability in this population in the 1990s which could lead to extinction within 200 years if not reversed. They also note that the population growth rate and extinction probability are more sensitive to changes in survival probability than to changes in fertility. Thus, to improve the situation for right whales, definitive action needs to be taken to reduce the level and severity of anthropogenic injuries and deaths. Right whale deaths and serious injuries have occurred all along the eastern seaboard and are not limited to the five high-use areas where right whales are seen most frequently. Although this is an important fact to consider as protective measures are proposed, focusing conservation strategies on the high-use areas would likely have the most immediate impact and should be pursued at least initially. Creating awareness of right whale conservation issues through education is certainly an important first step, yet considering the precarious status of right whales, further proactive measures are clearly needed. Disentanglement is one such effort that has met with positive results (only two out of the nine right whales that were disentangled suffered possibly fatal serious injuries), although these efforts may be considered more reactive than proactive. The effectiveness of these efforts strongly depends on the willingness of fishermen and others to report entanglements, the efficiency of response provisions and the severity of the entanglement. Disentanglement activity is extremely dangerous for the people involved and should not be considered a long-term solution. Other measures such as seasonal fishery closures and gear modifications may provide better long-term protection and are currently being implemented and evaluated for further improvements.

The impacts of ship traffic may be more complicated to remedy because the problem is international in scope. For example, measures focused only on US mariners would do little to alleviate the problem. However, a recent proposal developed by the US government to create two mandatory ship reporting systems for all ship traffic entering two defined high-use right whale areas along the eastern seaboard was adopted unanimously by the United Nations' International Maritime Organisation and was implemented in July, 1999 (NOAA Press Release 12/8/98). This system will increase awareness amongst mariners and hopefully reduce the level of interaction between right whales and ships. In other high-use areas, ships' routing measures to minimise travel distance through key habitats or speed restrictions may also be considered. In the long run, continued monitoring of the population throughout the extent of its range will be essential for evaluating the effectiveness of any measures undertaken to protect this severely endangered species.

\section{ACKNOWLEDGEMENTS}

Peter Best, Phil Clapham, Philip Hamilton, David Laist and the Scientific Review Committee of the Marine Mammal Commission kindly reviewed this manuscript. Data on mortality and serious injury were collected by a large number of research groups and individuals. We would especially like to thank the Center for Coastal Studies, East Coast Ecosystems, University of Rhode Island, Florida Department of Environmental Protection, Georgia Department of Natural Resources, Grand Manan Whale and Seabird Cruises, Brier Island Whale and Seabird Cruises, and the New England Aquarium Research Team for their long-term contribution and commitment to the photographic database which made these analyses possible. A special thanks to the many folks who have tackled the gory but essential job of necropsies, including Bob Bonde, Paul Brodie, Lisa Conger, Pierre-Yves Daoust, Greg Early, Philip Hamilton, Jon Lien, Bill McLellan, Jim Mead, Carolyn Miller, Michael Moore, Chris Slay and many others. Thanks to the Center for Coastal Studies for developing and expanding the disentanglement program, which has and will save the lives of right whales. Funding for this work has been provided by the National Marine Fisheries Service, the Marine Mammal Commission, Island Foundation, Inc., Massachusetts Environmental Trust and Davis Conservation Foundation.

\section{REFERENCES}

Aguilar, A. 1986. A review of old Basque whaling and its effect on the right whales (Eubalaena glacialis) of the North Atlantic. Rep. int. Whal. Commn (special issue) 10:191-9.

Angliss, R.P. and DeMaster, D.P. 1998. Differentiating Serious and Non-Serious Injury of Marine Mammals Taken Incidental to Commercial Fishing Operation: Report of the Serious Injury Workshop. 1-2 April 1997, Silver Spring, Maryland. US Department of Commerce, NOAA Technical Memorandum NMFS-OPR-13, 48pp.

Caswell, H., Fujiwara, M. and Brault, S. 1999. Declining survival probability threatens the North Atlantic right whale. Proc. Natl Acad. Sci. USA 96(6):3,308-13.

Donovan, G.P. 1992. The International Whaling Commission: Given its past, does it have a future? pp. 23-44. In: J.J. Symoens (ed.) Symposium «Whales: Biology - Threats - Conservation». Royal Academy of Overseas Sciences, Brussels, Belgium. 261pp.

Hamilton, P.K., Marx, M.K. and Kraus, S.D. 1998. Scarification analysis of North Atlantic right whales (Eubalaena glacialis) as a method of assessing human impacts. Paper SC/M98/RW28 presented to the IWC Special Meeting of the Scientific Committee towards a Comprehensive Assessment of Right Whales Worldwide, 16-25 March 1998, Cape Town, South Africa. [Available from the office of this Journal].

International Whaling Commission. 2001a. Report of the Workshop on Status and Trends of Western North Atlantic Right Whales. J. Cetacean Res. Manage. (special issue 2):61-87.

International Whaling Commission. 2000b. Report of the Workshop on the Comprehensive Assessment of Right Whales: A worldwide comparison. J. Cetacean Res. Manage. (special issue 2):1-60.

Kenney, R.D. and Kraus, S. 1993. Right whale mortality - a correction and update. Mar. Mammal Sci. 9(4):445-6. 
Knowlton, A.R., Kraus, S.D. and Kenney, R.D. 1994. Reproduction in North Atlantic right whales (Eubalaena glacialis). Can. J. Zool. 72(7):1,297-305

Kraus, S.D. 1990. Rates and potential causes of mortality in North Atlantic right whales (Eubalaena glacialis). Mar. Mammal Sci. 6(4):278-91.

Kraus, S.D., Moore, K.E., Price, C.A., Crone, M.J., Watkins, W.A., Winn, H.E. and Prescott, J.H. 1986. The use of photographs to identify individual North Atlantic right whales (Eubalaena glacialis). Rep. int. Whal. Commn (special issue) 10:145-51.

Osmond, M.G. and Kaufman, G.D. 1998. A heavily parasitized humpback whale (Megaptera novaeangliae). Mar. Mammal Sci. 14(1):146-9.
Reeves, R.R. and Mitchell, E. 1986a. American pelagic whaling for right whales in the North Atlantic. Rep. int. Whal. Commn (special issue) 10:221-54.

Reeves, R.R. and Mitchell, E. 1986b. The Long Island, New York, right whale fishery: 1650-1924. Rep. int. Whal. Commn (special issue) 10:201-20.

Rowntree, V.J. 1996. Feeding, distribution and reproductive behaviour of cyamids (Crustacea: Amphipoda) living on humpback and right whales. Can. J. Zool. 74(1):103-9.

Simpson, M.B. and Simpson, S. 1988. The pursuit of Leviathan: a history of whaling on the North Carolina coast. North Carolina Hist. Rev. 65(1):1-51. 